Research Article

\title{
A Study on Post-Sterilisation Failure in a Tertiary Care Hospital
}

\author{
Vivin Vincent', MK Saha ${ }^{2}$ \\ ${ }^{1}$ Associate Professor, Department of Community Medicine, ANIMS, Port Blair. \\ ${ }^{2}$ Professor, Department of Obstetrics and Gynaecology, ANIMS, Port Blair. \\ DOI: https://doi.org/10.24321/2454.8642.201914
}

\section{I $\quad \mathbf{N} \quad \mathbf{F}$}

\author{
Corresponding Author: \\ MK Saha, Department of Community Medicine, \\ ANIMS, Port Blair. \\ E-mail Id: \\ diraniims@gmail.com \\ Orcid Id: \\ https://orcid.org/0000-0001-6859-9484 \\ How to cite this article: \\ Vincent V, Saha MK. A Study on Post-Sterilisation \\ Failure in a Tertiary Care Hospital. Rec Adv Path \\ Lab Med 2019; 5(3): 5-7. \\ Date of Submission: 2019-06-29 \\ Date of Acceptance: 2019-09-10
}

\section{$\begin{array}{llllllll}\mathbf{A} & \mathbf{B} & \mathbf{S} & \mathbf{T} & \mathbf{R} & \mathbf{A} & \mathbf{C} & \mathbf{T}\end{array}$}

Background: Female sterilization or tubal ligation is the most accepted method of contraception in India. The most popular method used in female sterilization in India is the laparoscopic tubal occlusion. Sterilization failure may occur, though rates are as low as around 0.1$0.3 \%$.

Objectives: The objectives of the study states to assess the prevalence of ectopic pregnancy and to study the types of ectopic pregnancies.

Materials and Methods: This prospective study was conducted between January 2011 to December 2018 in the Obstetrics unit at GB Pant Hospital, ANIMS, Port Blair. Records of cases of post sterilization failure were studied. The results were described in proportions.

Results: $76 \%$ of the sterilizations were done during interval period. $56 \%$ of recurrence occurred after 2-5 years of surgery. $61 \%$ of the pregnancies after sterilisation failure were ectopic pregnancies.

Conclusion: The chances of post sterilization failures though minimal, must be explained to the patients and when to seek medical help, to diagnose at the earliest.

Keywords: Contraception, Post-Sterilisation, Tubal Ligation

\section{Introduction}

Fallopian tube ligation commonly called as female sterilization is a well-known, common and widely practised contraception method worldwide and also in India. Around 5-6 million sterilization are done annually. It accounts to $98 \%$ of the permanent contraception method. Tubectomy method of contraception contributes to $62 \%$ of contraceptive procedures done. Laparoscopic tubal occlusion is the most common practised method in India among the female sterilization techniques. ${ }^{1}$

Minilaparotomy, laparoscopic sterilization and hysteroscopic methods are the common methods of female sterilization practised in India, Minilaparotomy is the most popular postpartum sterilization practised in our Country. ${ }^{2}$

Though tubal ligation done by Minilaparotomy is not a complicated procedure, a size of the incision is comparatively large. Post-operative wound infection and pain are widely reported. The duration of hospital stay is also long. On the contrary in laparoscopic sterilization technique, the length of incision is smaller and the duration of stay in the hospital is also less needs. The only key feature in laparoscopic procedure is the need for a well-trained gynaecologist. ${ }^{2}$

However, unfortunately in some women; sterilization failure may occur though rates are as low as around $0.1-0.3 \%{ }^{3}$ 
Post sterilization failure commonly presents as ectopic pregnancy and it accounts for around $12 \%$ of all ectopic cases. ${ }^{4}$ This study has been planned to assess the prevalence of ectopic pregnancy in our hospital

\section{Objectives}

The objectives of the study states:

- To assess the prevalence of ectopic pregnancy

- To study the types of ectopic pregnancy

\section{Methodology}

This prospective study has been conducted in the study was conducted between January 2011 to December 2018 in the Obstetrics unit at GB Pant Hospital, ANIMS, Port Blair on 67 subjects. Records of post-sterilization failure cases were studied for age of occurrence, method of sterilization, timing of surgery, duration between surgery and occurrence of sterilization failure, location of the pregnancy etc. and the results were analysed using SPSS 16 and tabulated.

\section{Result}

The maximum number of sterilization failure was between the age group of $26-30$ years (43\%). Laparotomy was the most common procedure done (64\%). Around $76 \%$ of the sterilization was done during interval period. Around $56 \%$ of recurrence occurred after $2-5$ years of surgery. $61 \%$ of the sterilisation failure pregnancies were ectopic pregnancies.

Table I.Distribution of study population according to various parameters studied

\begin{tabular}{|c|c|c|}
\hline & Frequency & Percentage \\
\hline \multicolumn{3}{|c|}{ Age group } \\
\hline $20-25$ & 16 & 23.88 \\
\hline $26-30$ & 29 & 43.28 \\
\hline $31-35$ & 12 & 17.92 \\
\hline $36-40$ & 8 & 11.94 \\
\hline $41-45$ & 2 & 2.98 \\
\hline \multicolumn{3}{|c|}{ Method of tubectomy } \\
\hline Minilaparotomy & 12 & 17.91 \\
\hline Laparotomy & 43 & 64.18 \\
\hline Laparoscopic Sterilization & 12 & 17.91 \\
\hline \multicolumn{3}{|c|}{ Timing of Surgery } \\
\hline Puerperal sterilization & 12 & 17.91 \\
\hline Interval sterilization & 51 & 76.11 \\
\hline During LSCS & 4 & 5.98 \\
\hline \multicolumn{3}{|c|}{ Duration between surgery and sterilization failure } \\
\hline$<2$ years & 11 & 16.42 \\
\hline $2-5$ years & 38 & 56.72 \\
\hline $5-10$ years & 16 & 23.88 \\
\hline
\end{tabular}

\begin{tabular}{|c|c|c|}
\hline 10-15 years & 2 & 2.98 \\
\hline \multicolumn{3}{|c|}{ Implantation site } \\
\hline Intrauterine & 24 & 35.83 \\
\hline Ectopic & 41 & 61.19 \\
\hline Others & 2 & 2.98 \\
\hline
\end{tabular}

\section{Discussion}

Laparotomy was the common procedure done (64\%). Rathod S, Samal SK ${ }^{5}$ reported a similar result (71.4\%). Ectopic gestation was $61 \%$. Vessey $\mathrm{M}$ et al. ${ }^{7}$ reported $44 \%$ of ectopic pregnancy, while Shah JP et al. ${ }^{6}$ reports a lower prevalence of $4.53 \%$. Rock JA et al. observed "recanalization" and "tuboperitoneal fistulas" as a main cause for recanalization. ${ }^{8}$ They also noticed development of endometriosis in the tip of the proximal segment of the ligated tube in a high percentage of patients. Prior to the development of the fistula, the tube appeared to have been dilated. Progressive extension of the endometriosis, perhaps aided by internal pressure, seems to have resulted in penetration of the muscular wall of the tube with subsequent fistula formation either in the broad ligament or in the peritoneal cavity. PID, endosalpingitis, necrosis or tubal atrophy are the other associate factors. ${ }^{8}$ In surgeries done during puerperal period, Spontaneous tubal reapproximation common occurs because the tubes will be dilated during that period, and hence more chance for tubal reanastomosis and recanalization. blind pouches and slit like spaces will be formed during reanastomosis which are the common sites of ectopic implantation. ${ }^{9}$ Stock $\mathrm{RJ}$ et al. suggests that fluid movement inside the remaining tube may favour implantation. ${ }^{10}$

\section{Conclusion}

The chances of post sterilization failures though so minimal, must be explained to the patients. The chances of ectopic and hence mortality is high in post sterilization failures and hence the patients must be asked to come for immediate review once they have a missed period for further evaluation.

\section{Conflict of Interest: None}

\section{References}

1. Date SV, Rokade J, Mule V et al. Female sterilization failure: Review over a decade and its clinicopathological correlation. Int J Appl Basic Med Res 2014; 4(2): 81-85.

2. Layde PM, Peterson HB, Dicker RC et al. Risk factors for complications of interval tubal sterilization by laparotomy. Obstet Gynecol 1983; 62: 180-184.

3. Sarella LK. Evaluation of post sterilization ectopic gestations. Int J Reprod Contracept Obstet Gynecol 2017; 6: 1503-1506. 
4. Chakravarti S, Shardlow J. Tubal pregnancy after sterilisation. Brit J Obstet Gynaecol 1975; 82(1): 58-60.

5. Rathod S, Samal SK. Clinical analysis of post sterilization failure cases in a tertiary hospital. Int J Reprod Contracept Obstet Gynecol 2017; 6: 3294-3296.

6. Shah JP, Parulekar SV, Hinduja IN. Ectopic pregnancy after tubal sterilization. J Postgrad Med 1991; 37(1): 17-20.

7. Vessey M, Huggins G, Lawless M et al. Tubal sterilization: findings in a large prospective study. $\mathrm{Br} J$ Obstet Gynaecol 1983; 90(3): 203-209.

8. Rock JA, Parmley MA, King TM et al. Endometriosis and the development of tubo peritoneal fistulas after tubal ligation. Fertil Steril 1981; 35(1): 16-20.

9. Horuine $\mathrm{LH}, \mathrm{O}^{\prime} \mathrm{H}$ ara KE. Failed tubal sterilisation as an etiologic factor in ectopic tubes pregnancy. Fertil Steril 1978; 29: 509-511.

10. Stock RJ, Nelson KJ. Ectopic pregnancy subsequent to sterilisation: histologic evaluation and clinical implications. Fertil Steril 1984; 42(2): 211-215. 